\title{
The Polyhedral Self: A Pirandellian Psychoanalytic Study
}

\author{
Madiha Zulfiqar \\ University of Bahrain \\ English Language Center, Sakhir \\ Bahrain
}

\begin{abstract}
In accordance with Luigi Pirandello's idea of self, this paper intends to reveal the transitory nature of self by stripping off the excessive artifice of physical human existence and the resulting sickness, and also by theorizing that the individuality, identity and normality are mere false edifices. Thereupon, pursuing this claim, the paper proceeds to analyze protagonist of Pirandello's novel, which functions as mouthpiece for philosophical ideas of Pirandello, echoing throughout the selected narrative from vast range of Pirandello's writings. The paper will also be analyzing and presenting all those factors and those certain human behaviors that join together in the construction of self in the light of psychoanalytic theories of Sigmund Freud, Carl Jung and Alfred Adler.
\end{abstract}

Keywords: Fragments of self, Illusion, Pirandello's idea of self, Self, Psychoanalysis.

\section{Introduction}

One, No-One and One Hundred Thousand (1926)(Uno, Nessuno e Centomila) by Luigi Pirandello is a marvelous piece of literature that attempts to give voice to certain philosophical and idealistic views about self as retained by the author. Thus, revolving majorly around the psychological aspects of philosophies it expresses them all through complicated thoughts of the protagonist Vitangelo Moscarda. Pirandello takes enough pains to depict even the minor psychological factors involved in and responsible for certain actions of the hero and for incidents in the novel. Therefore, in the following paper, psychological units engrossed in the construction of self of the protagonist are elaborated through psychoanalytic examination of certain elements. Furthermore, application of specific postulates of psychoanalytic theories on the selected parts of text also facilitates analyzing the self of Moscarda in particular and of humans in general. Some of the important features to which special attention during this analysis is paid include; trauma, otherness, perception of self, complexes, fear, illusion and reality and at last, communique collapse.

Moreover, the action in the novel is significantly psychological because the subject matter of the novel and almost all the important events originate from and ultimately relate back to mind of the hero. The opening scene brings us the scenario of a typical home, wife is doing chores and her man, Moscarda, is clinging to a mirror inspecting his nose. His wife shocks him by revealing the tilt of his nose of which Moscarda is unaware. The advent of this knowledge about his nose makes him very suspicious about the externalities of existence. Therefore, the novel progresses with his explorations of different perspectives; how people see him and how they distinguish each other. However, becoming too attentive about the appearances of people, their movements and their suddenly changing behaviors, he tends to search for the possible layers of their personalities. In the meantime, an urge to know his own self inspires him, to know himself from outside as well as from inside the shell of his body through which people see and know him. Consequently, he starts trying to grasp a picture of his personality in complete solitude. Meanwhile his speculations, it dawns upon him that each of his acquaintances cherishes an unreal or imaginative picture of Moscarda whatsoever suits to their perception of him, and thus leading to the generation of hundred thousands of Moscardas, and each differing from the others'.

\section{Psychoanalytic Study of Moscarda}

Psychoanalytic examination of the character of Moscarda accompanies the evaluative study of previously mentioned factors because of their eminent contribution in the formation, deformation, sustenance and destruction of self.

\subsection{Trauma}

According to Charcot (1825) and Freud (1856), trauma is basically a damage to one's psyche that occurs as a result of severely distressing incident in a person's life, and thus depriving him of the ability to integrate his emotions in a normal manner. The journey of Vitangelo Moscarda into the realms of self is instigated by a trauma, the trauma of a physical discovery by an external eye. At the very start of the novel, his wife mentions that his nose bends to one side. This is something he has never known about himself while it has always been a part of his personality from the very first day of his life. 
Simultaneously, Moscarda undergoes a shock of his ignorance and thinks, "I didn't know well even my own body, my most personal possessions: nose, ears, hands, legs" (Pirandello, 1926, p.5). Once it reveals to him, follows a chain of traumas that he suffers. Meanwhile approaches another discovery to nip him down during a consideration of people and their behaviors, he identifies that his own behavior is erred. Notwithstanding this revelation he feels jerked on detection of disparity in his conduct with different people. His unnoticed varying attitude with his wife, employees and friends drags him more traumatized. Therefore, this coarse shift of his behavior in the community alternatively requires observing himself in solitude. Solitude and its spontaneity turn out to be an impossible thing when pursued intentionally by Moscarda but he wanted to see himself from the eyes of an outsider. However, once seeing him in mirror he couldn't make it that it was his own image replicating in front of his eyes and again amazed at this he reflects, "was that really my image, glimpsed in a flash" (Pirandello, 1926, p. 13). At that moment his senses recognize a person existing in him whom people see as him but he doesn't, that person has lived all these years with him and he has not been aware of it, not even doubted for fraction of a second. It seems as the trauma has prevailed over his life like a thick cloud and he cannot escape it no matter how long he runs since he believes "I was obsessed by the thought that for others I was not what till now, privately, I had imagined myself to be" (Pirandello, 1926, p.7). In lieu of his disappointments, because of smashing of his expectations, he starts feeling more vulnerable. These happenings may seem very insignificant to someone else but for a speculative person like Moscarda they have a large effect sufficient to change him for life. Through Moscarda, Pirandello seems to suggest the role of trauma as an eye/mind opener for us as humans. His intentions of making people realize the importance of trauma can be seen very clearly as he tries to shift the image of trauma from merely a painful experience to a life-changing trigger. Trauma brings a person closer to the door of self-speculation and exploration of one's real being which otherwise would not have been possible that easily.

\subsection{Otherness}

After having a glance at the unknown face of his personality, Moscarda commits to probe into the whole possible range of his person that is an open secret to people except him. Ignorant of all those hundred thousand Moscardas who subsist inside him, Moscarda continues to pursue that one 'other' he saw in the mirror. Subsequently, during this toil to explore that one other, when he comes to know that this is not the only other present in him but more than hundred thousands, his awe turns into bewilderment. At this level of exploring the psychological aspects of Moscarda's self, the association of the other with concept of self of Pirandello takes up a very dramatic harmony. Accordingly his mind and his soliloquies show an apt conformity of his notion of 'other' with Lacan's postulate of otherness of self. However, the other provided by Lacan suggests an alienation of oneself to itself. In the same vein many a forms of Moscarda's other are found that vary from time to time. In the first place, a worth mentioning twin of the other, that haunts Moscarda all the way long to his recognition of self, is mirror. The self as presented by Pirandello is occurring to be closer one to the self which Lacan had preserved.

However, through all this pursuit of Moscarda, Pirandello indirectly persuades the reader to approach the last provision of Lacan's psychoanalytic theory, the mirror stage, which functions as a platform for the illustration of the self. This inclusion of mirror by Pirandello also allows one to consider an underlying otherness about all his portrayed characters. Moscarda's venture of recognizing himself as him one time and seeing himself as the other in the same mirror completely conforms to Lacan's idea of I and the other as Moscarda exhibits his experiment in these words, "We are two: I here, he there, in the mirror" (Pirandello, 1926, p.17). Accordingly Moscarda passes from a stage of unawareness to awareness by identifying himself and his other through mirror.

Nevertheless, this sense of otherness is not restrained to the character only and an otherness of the opinion and vision can be perceived throughout the novel. He further elaborates his thoughts as, "I am that outsider I glimpsed by surprise in the mirror: him, and not me, as I know myself" (Pirandello, 1926, p.13). The outsider on one hand is he to himself and realization of this otherness makes him conscious of his outlook, while on the other hand the very same otherness inspires curiosity for inspecting the structure and faces of self. Thus the resultant madness, imposed though, also embodies this otherness of self in Moscarda. Therefore, in search of a way out of this dilemma, he opts for madness but in doing so he adds one more to the uncountable list of faces of his self.

\subsection{Perception of Self}

Pirandellian researches more than often refer towards certain modes of being and living in the present-day world as an equally important factor in determining the self of any person. At the same time extinction of a unitary self is found recurrently stressed and what is revealed is its multilayered and fractured nature. On the other hand self is also considered as a construct for which identity, individuality, and physical existence of the character function as constituent elements. However, this sense of self may vary from person to person in its range of strength or weakness. Again, starting his journey into the world of self, Moscarda realizes that self is the name of an always changing season, a season that changes every moment and in every possible dimension. 
Every passing moment brings changes in one's nature, priorities, aspirations and his needs. Similar concept is employed by Pirandello in his play 'Six Characters in Search of an Author' (Pirandello, 1921) in which Father becomes a mouthpiece of his concept of always changing self. However, Moscarda discovers the multiplicity of his self while observing shifts of his behavior and thus finds out that he has not a single self which could be labeled as original self of Moscarda. He declares that, with the discovery of the hundred thousand Moscardas that I was, not only for others but also for myself, all with this name of Moscarda, ugly to the point of cruelty, all inside this poor body of mine that was also one, one and, alas, no one (Pirandello, 1926, p.14), there couldn't be found any of his hundred thousand selves located at such levels of legitimacy where he could entitle it as real.

Furthermore, as far as Moscarda's apprehended sense of self is concerned, until now it has been revealed as disjointed since he severely feels himself divided into more than hundred parts. Then, this instability in his self also affects his outlook towards life and people. For the sake of solving this dilemma and to come out of the flux of self he chooses to pretend mad. Whereas, his pretended insanity is only a mean to bring all the disjointed pieces of his self together, externally it appears to people as a loss of memory and sanity that makes him act mad, in this way there occurs a huge contradiction between external and internal perceptions of actions of Moscarda. His motive behind adopting madness is only to string together his selves as one since these excessive layers baffle him. On the contrary, the people around him think of him as a mad person who has lost his memory and can exercise no control over his thoughts.

In addition, the incident of Moscarda's argument with his wife is considerable enough to measure the level of success he achieves in becoming one for all. He argues with his wife and annoys her, when he mentions her calling him Gengi as a betrayal, taking him as retarded, she leaves him. As a result of this breakup, Moscarda begins to recoup the sense of his self as one, as a unified subject, master of his will and capable of proving it to others in a moment. His sense of success can be read through his thoughts as, "I decided to discover who I was at least for those closest to me, my socalled acquaintances, and to amuse myself by dismantling spitefully the me that I was for them" (Pirandello, 1926, p.22). The assertion of his will for oneness goes along with his yearning for internal stability amidst this instable world. However, multiplicity and diversity of Moscarda's being mostly wins over his fierce reassertion of his unanimity and this rarely felt sense of oneness is defeated. Pirandello takes up a stance to present that becoming one and same for all your acquaintances is only possible if you go mad or get your mind retarded. Unavoidably, the persona of any individual is subject to as many images as many eyes glance on it.

\subsection{Complexes, Fears and Identity}

Exploring Moscarda further in pursuit of his self, this segment of the psychoanalytic study takes along the examination of certain possible complexes. This is done through deriving conformity between the concept of inferiority complex put forward by Alfred Adler and the situation of Moscarda. Adler recommends that any individual can retain a kind of complex because of some deficiency in his personality, especially if it is some visible physical defect. However, this complex can be stern or mild because of the criticism that individual faces during his earlier childhood. Most of the times recommended cure for the complex generally rests in compensations, through which the sufferer or victim manages to overcome the complex. On the first place, if the complex is not embedded very deep in individual consciousness, it can simply be eradicated by providing compensation for it. On the other hand, if the roots of this complex probe deep down a person's unconscious it cannot be cured with compensation only, and takes the form of a higher level of complex called superiority complex. Thus, Adler proposes that a superiority complex is actually an inferiority complex in its acutely worsened form. In this superiority complex the individual seeks for superiority over others, builds castles in the air and also tries to undertake unrealistic \& unachievable goals for his life.

Moscarda's self when viewed through this window, shows that his bewilderment along with the search of the self, starts when his wife mentions the bent of his nose and the circumflexed-accent like eyebrows he had. Further, there are also enough chances that Moscarda had faced in his younger years a higher criticism than he deserved and might has been concealing a secret complex all his life. The complex reaches its height when his wife not only notices but also mentions it and afterwards his friend too whom he asks about his nose. However, it's not the discovery of a bent nose that shocks him; it is the discovery of people's knowledge of his defects. His bewilderment might be because of this underlying feeling of social inferiority. He might be aware of these physical deficiencies but does not want others to know about these. Apart from these, his clinging to the mirror at the start of the novel indicates his special attention towards his nose. There has definitely been something about it that he does not want others to know probably a bent of nose or something else. Therefore, bringing in Adler's proposition as for Moscarda's situation, it can be easily inferred that he has been suffering from intense inferiority complex. Though it remains dormant earlier but comes on the surface after his encounter with facts from someone else's tongue. Or simply it can be the complex of lack of his knowledge about himself as he realizes that "I don't know well even my own body, my most personal possessions" (Pirandello, 1926, p.5). This thought causes him a feeling of sickness and the ultimate fear of going mad with all spirit and body. 
However, rise of his concern to what people think of him seeing through his appearance to a frustrating level symbolizes that complex again.Again, reminding Adler's two kinds of complexes: primary complex and secondary complex, Moscarda's position can be more understandably explained. According to Adler the primary complex is the one faced during early age, most probably during early childhood when sense of self is under construction. This kind of complex often gets buried in unconscious, with the passage of time and growing age. On the other hand, the secondary complex is a complex of grown up age; it hits its victim when he stands as a full-fledged adult and a responsible figure of society. In this light, Moscarda is revealed to be a prey to both of these primary and secondary complexes simultaneously. His physical appearance is definitely something that brings him into primary complex prior to the secondary which originates on the basis of his little knowledge about himself. However, when combined both of these complexes lead him to retrospect about his place in society, his dealings with people, his multifaceted behavior and above all mysterious segments of his personality. Some consequences of suffering through complexes are also explained by Adler i.e. the sufferer can be seen striving for three things; striving for ideal, striving for compensation and striving for superiority. In addition, the victim finds his destination in succeeding to reach these three targets since they work as a veil for his complexes. Whereas, in case of Moscarda all these three strivings merge into one: his struggle to become a single identity for everyone around him. At this point of the research, Pirandello has enormously provided an accurate universal mouthpiece for humans in the form of Moscarda who strives for hiding the complexes and in the very pursuit he reveals them all. The shelter of false artifice is just temporary but still humans do struggle to keep it together and resultantly confuse their very reality with the other and complexes, pushing themselves away from knowing their own self.

\subsection{Illusion and Reality}

In Pirandello's literature, the incidences of metaphysical reality areexaggerated more than the occurrence of reality. The illusions and pretensions are scattered far and wide and it is equally true that materialization of this fact is a cause of tragic pain in the characters. Further consideration, however, discovers another pattern. There is a prevalent kind of social or socio-psychological realism which is the most important element in many of his works. Psychoanalytic examination of character of Moscarda uncovers the conflict of illusion and reality instilled by Pirandello. Coming into existence with the life of man, this conflict has not been resolved until now. Mirror and image collectively play a conflict-enhancing role. However, the depiction of doubling or other permits Moscarda to visualize his appearance as an object.

At the same time it always raises the question of illusion which would threaten this new notion of reality that mirror offers. Just as Moscarda couldn't accept what he sees in the mirror as the image of real Moscarda when he tries to get a glimpse of himself from other person's eyes. A sudden encounter with his image in mirror astonishes him and makes him question if it was really he. If he recognizes and accepts that image as him, it throws him into complete estrangement from even himself. Regardless of the mirror, pursuit of ideal also shoves him into the clash between illusion and reality. The ideal keeps on oscillating in between the spheres of illusion and reality, chased by the individual. Once it falls into the category of illusion and the next moment the ideal seems standing in the realm of reality. However when the individual reaches back into reality, the ideal fades into illusion and this play of illusion and reality goes on.

In this way Pirandello successfully explains the role of ideal incorporated in the construction of self. Moscarda's pursuit for one self victimizes himas a mania when he searches for his ideal, (i.e. being one for all). Though his madness retains the place of only an illusion but this fact is remote to him at the time he decides to pretend mad. First, to realize his plan, he comes up to this illusion with a measure of lucidity. However, the most illusory moments for him are those in which he sees his madness echoed most clearly. So when he sees the unavoidable multiplicity of his being and his failure to control or even to shape its endless forms, he drops a filter of madness on it, pushing himself into illusion in the name of reality. He shares: Perfectly aware, as you see, I continued walking along the high road of madness, which was, in fact, the road of my reality, as it now very clearly opened before me, with all the images of me, alive, mirrored, proceeding with me (Pirandello, 1926, p.81, 82).As a result, leaving people in a frustrating confusion of which one is the real and which one is imposed. This pursuit also establishing the fact that in Pirandello, every character's attempt to create a personal reality is for the sake of acquiring an acknowledged position in the social order. Many of the Pirandellian characters are unsuccessful in their efforts because what they consider as logic is considered a delusion by people. However, Moscarda's conflict is not limited to himself only but also to the multiplicity of people's faces, bringing about a perplexity of illusion and reality.Nevertheless, the role of conflict of illusion and reality in Pirandello's works initiates the idea that the people labeled as mad or insane still have the ability for logic and reasoning, but they do this from a different point of view which has been less acceptable or seemingly impractical. It is also proposed that there is always some sanity behind the curtain of insanity; Pirandello, however, seems to universalize this conflict through Moscarda's misery. 
People are in conflict because of Moscarda and Moscarda is miserable because of people, conceivably everyone in the novel is suffering through this conflict of reality and illusion. One person's reality becomes others' illusion while for others their reality is most authentic and appealing. Similarly, this concept has been established as central theme in a remarkable play of Pirandello Six Characters in Search of an Author (1921). In which Pirandello proposes through character of Father that a person's reality of today can turn out to be an illusion of tomorrow. Keeping that in view for Moscarda and his assumed madness, it can also be supposed that Pirandellian hero is able to see beyond physical realities, for him the tremendous illusions and realities exist at the same place and the same time. He explains this proposition through an incident when Moscarda returns home from outside, he finds his employee of the bank Quantorzo in conversation with his wife Dida. Although there were three people physically present yet he states that for him there were more than three realities and simultaneously more than three illusions. As he states there happened the presence of eight realities and eight illusions at the same time in his living room;

1) Dida, as she was for herself;

2) Dida, as she was for me;

3) Dida, as she was for Quantorzo;

4) Quantorzo, as he was for himself;

5) Quantorzo, as he was for Dida;

6) Quantorzo, as he was for me;

7) Dida's dear Genge;

8) Quantorzo's dear Vintangelo (108).

Further, excluding himself from the count, he sees eight different selves present there. Dida what she thinks herself to be, Dida what she means to Moscarda and Dida what she seems to Quantorzo. Similary, remaining include Quantorzo as he assumes himself, his version of Dida and what he is for Moscarda, and last Moscarda's picture by Dida and Quantorzo. However, Moscarda does not include himself in any reality, the reality of his person for himself since he does not consider himself a reality, as he states clearly, "For myself I had no personal reality, I underwent a kind of constant melting, fluid, malleable; the others knew me each in his way" (Pirandello, 1926, p.43). Similarly, applying this phenomenon on the twin illusions of these realities, the reality of each of them becomes illusion for the other in the same flow. The fact is exposed through the pen of Pirandello but words of the protagonist as, "Human being acts necessarily through forms, the appearances he creates for himself, to which we give the value of reality. A value that changes, naturally, according to how the being appears to us, in that form, in that act" (Pirandello, 1926, p.62). Owing to the change of time and circumstances, a person does not remain what he has been in the past, everyone sees himself different at present from what he has been previously. Therefore, the thought provoking idea has conformity to the changing nature of reality of man on one hand and on the other hand it raises the question of what actual illusion is. He relates:

There is in me and for me a my reality:

the one I give myself; a your reality in you and for you,

the one you give yourself;

they will never be the same either for you or for me (Pirandello, 1926, p.32).

This study of characteristic illusion and reality also relates back with protagonist's pursuit of ideal and further his madness. However, it has a significant alienating effect on his mind since he realizes the things that other people around him have not even thought of.

\subsection{Communiqué Collapse}

Last but not the least to join in the process of self-construction is ability to communicate, with oneself and about oneself to the world around. Pirandello presents this ladder to self as one bold out of the whole list of important factors responsible. However he presents through this selected mouthpiece with name of Moscarda. Having gone through all the traumas and realizations, at last, Moscarda decides to put into words his experience of realizing so many others living inside him. During the moments of intended expression he again faces a blow in the form of breakdown of his ability to communicate. The more he tries to express his thoughts about countless layers of personality and the phenomenon behind shifts of behavior, the more he becomes miserable since nobody understands him. At this point in his life it wouldn't be wrong to connect with the theory of Lacan which he termed as the third stage of psychological development, the symbolic order initiates when one starts to use language. He suggested that very entrance into language pushes one utterly away from real as the words from mouth can never withhold the idea generated and carried in one's mind. 
In addition, it is also noteworthy that signifier and signified happen to vary for every next person, since even a single word does not retain same meaning for all the people who say or hear it. As a result language fails and communication dies. So is with Moscarda, his trials to keep in touch with the real and still clinging to transfer his experience in language comes out to be impossible, causing him to suffer again. Going from person to person in search of someone who could understand him in the reality of his experience, he eventually gets shoot by a female friend. The incident shows frailty of the ties of communication between humans, and also the reason for which Moscarda says, "We thought we understood each other; we didn't understand each other at all" (Pirandello, 1926: p.32). However, as per concept of self forwarded by Pirandello, a person is never a whole. He is divided into fragments and layers of personality, and has no control over which face to show or take the charge at one moment and which one to hide; all this is decided by self. On the other hand Pirandello acknowledges that the communiqué collapse also arises from the fact that an individual's self does not remain the same over all the due course of life, not even with the one person because he is simply devoid of the capacity. His thoughts and preferences change every moment and so do his connections. This is what Moscarda tries to put in the language but cannot make other people comprehend his point and instead of decreasing, his agony increases.

Likewise, according to Lacan this experience in his communication can be termed as the real stage of his, Moscarda's, psychological upbringing. Real stage in the psychological process of mental development, as proposed by Lacan, covers the span when the individual is not aware of his relation with others and the process of identification has not started yet. At this stage a person does not necessarily have any distinction between himself and his environment. Interpreted in terms of psychological development of Moscarda, it indicates the time when he lives in a sheer ignorance of his personality including physical features. It also marks the time or the life most probably that he has spent before the start of the novel. Moscarda is in his real stage when he does not know anything about his nose, living totally unaware of how people perceive of him, his place in people's life and social circle and also about various faces of his own self.

Therefore, as discussed earlier, entrance into language pushes one totally away from real; it proves to be a hindrance in Moscarda's way of knowing himself. He tries to communicate about his pursuit of real self so that he could drop his imposed veneer but nobody appreciates him. Further, he is considered insane for thinking like that, of which he takes benefit and decides to keep this insane self as his recognition for all the people around him, so thatthey can identify him as one instead of different. For which he ultimately gets succeeded, one superficial coating of madness hiding all the other images of his persona.

\section{Conclusion}

This piece of writing, after examining into the details of the concept of self as presented by Pirandello, provides a framework for analyzing self and its relevant enigmas in contemporary era as well. The reason for which can also be assumed that almost half of the total population of the world today is obsessed with the questions like who I am, why I am so, and why I do so. At the same time, this paper also opens the doors for solution of certain psychological issues being encountered in 21 st century.

\section{References}

Lindzey, G., \& Aronson, E. (Eds.). (1968). The handbook of social psychology (2nd ed.). Addison-Wesley. Jacoby, M. (1990). Individuation and narcissism: the psychology of self in Jung and Kohut.(1 $1^{\text {st }}$ ed). Routledge. James, W. (1902). The varieties of religious experience: a study in human nature. New York: Longman, Green \& Co. Mendelowitz, E. (2011). Humanitas- Pirandello's late Mattia Pascal.Society for Humanistic Psychology, Article 32. http://www.apadivisions.org/division32/publications/newsletters/humanistic/2011/01/late-mattia-pascal.aspx

Pirandello, L. (2003). The Late Mattia Pascal.ProjectGutenberg.http://gutenberg.net.au/ebooks03/0300381.txt (Original work published 1923)

Pirandello, L. (1926) Uno, Nessuno e Centomila [One, No One, and One Hundred Thousand].The Lightening Source.

Quinn, L. M. (1989). Relative identity and ideal arts: The Pirandello conflict and its political analogy. Journal of Dramatic Theory and Criticism, Article 1713.https://journals.ku.edu/jdtc/article/view/1713

Sedikides, C. \& Spencer, S. J. (Eds). (2007). The self. Psychology Press.

Sartre, J. P. (1943). Being and nothingness.A phenomenological essay on ontology. Gallimard.

Dian, T. (1999) Six characters in search of an author: A study guide. NVCC, Article 252. http://novaonline.nvcc.edu/eli/eng252/pirandellostudy.htm 